\title{
Growth, clinical chemistry and immune function in domestic piglets fed varying ratios of arachidonic acid and DHA
}

\author{
Cynthia Tyburczy ${ }^{1}$, Kumar S. D. Kothapalli ${ }^{1}$, Woo Jung Park ${ }^{1}$, Bryant S. Blank ${ }^{2}$, Ying-Chun Liu ${ }^{3}$, \\ Julie M. Nauroth ${ }^{3}$, J. Paul Zimmer ${ }^{3}$, Norman Salem $\mathrm{Jr}^{3}$ and J. Thomas Brenna ${ }^{1 *}$ \\ ${ }^{1}$ Division of Nutritional Sciences, B38 Savage Hall, Cornell University, Ithaca, NY 14853, USA \\ ${ }^{2}$ College of Veterinary Medicine, Cornell University, Ithaca, NY 14853, USA \\ ${ }^{3}$ Martek Biosciences Corporation, Columbia, MD 21045, USA
}

(Received 10 February 2011 - Revised 5 April 2011 - Accepted 2 June 2011 - First published online 1 November 2011)

\section{Abstract}

In the USA, infant formulas contain long-chain PUFA arachidonic acid (ARA) and DHA in a ratio of 2:1 and comprise roughly $0.66 \mathrm{~g} / 100 \mathrm{~g}$ and $0.33 \mathrm{~g} / 100 \mathrm{~g}$ total fatty acids (FA). Higher levels of dietary DHA appear to provide some advantages in visual or cognitive performance. The present study evaluated the effect of physiologically high dietary ARA on growth, clinical chemistry, haematology and immune function when DHA is $1.0 \mathrm{~g} / 100 \mathrm{~g}$ total FA. On day 3 of age, formula-reared (FR) piglets were matched for weight and assigned to one of six milk replacer formulas. Diets varied in the ratio of ARA:DHA as follows (g/100 g FA/FA): A1, 0.1/1.0; A2, 0.53/1.0; A3-D3, 0.69/1.0; A4, $1 \cdot 1 / 1 \cdot 0 ;$ D2, $0 \cdot 67 / 0 \cdot 62 ;$ D1, 0.66/0.33. A seventh group was maternal-reared (MR) and remained with the dam during the study. Blood collection and body weight measurements were performed weekly, and piglets were killed on day 28 of age. No significant differences were found among any of the FR groups for formula intake, growth, clinical chemistry, haematology or immune status measurements. A few differences in clinical chemistry, haematology and immune function parameters between the MR pigs and the FR groups probably reflected a difference in growth rate. We conclude that the dietary ARA level up to $1.0 \mathrm{~g} / 100 \mathrm{~g}$ total FA is safe and has no adverse effect on any of the safety outcomes measured, and confirm that DHA has no adverse effect when ARA is at 0.66 g/100 g FA.

Key words: Arachidonic acid: DHA: Growth: Long-chain PUFA: Piglets

Arachidonic acid (ARA, 20:4n-6) is a natural component of human breast milk and is routinely added to infant formulas along with DHA (22:6n-3). Both are long-chain PUFA (LCPUFA) that contribute to normal growth and development during the perinatal period, serving as essential structural components of central nervous tissue and precursors for lipid signalling molecules ${ }^{(1)}$. In 1994, the $\mathrm{FAO} / \mathrm{WHO}^{(2)}$ set recommendations for ARA and DHA to be included in infant formula at $0.66 \mathrm{~g} / 100 \mathrm{~g}$ and $0.33 \mathrm{~g} / 100 \mathrm{~g}$ total fatty acids (FA), respectively. Worldwide levels of ARA and DHA in breast milk prove variable, however, comprising $0 \cdot 47$ (SD 0.13) g/100 g (range $0 \cdot 24-1.0 \mathrm{~g} / 100 \mathrm{~g}$ ) and $0.32(\mathrm{SD} 0 \cdot 22) \mathrm{g} / 100 \mathrm{~g}$ (range $0.06-1.4 \mathrm{~g} / 100 \mathrm{~g}$ ) of total FA, respectively ${ }^{(3)}$, with the wide range of DHA attributed largely to maternal diet. As a guide for infant formulas, the worldwide variability in breast milk levels presents a challenge for optimising the LCPUFA composition of formula to support proper development of the infant central nervous and immune systems.
Clinical studies designed to determine the optimal level of LCPUFA in infant formula are limited in the safety parameters that they can measure, focusing predominantly on growth outcomes and blood LCPUFA status. Here, two large metaanalyses have recently demonstrated a negligible effect of LCPUFA supplementation on growth outcomes ${ }^{(4,5)}$, while functional outcome studies consistently report visual and cognitive benefits of LCPUFA to formula-fed infants compared with infants consuming an LCPUFA-free formula ${ }^{(6)}$. Studies specifically addressing the level of ARA or the ARA:DHA ratio in formula are rare and limited to only a few preclinical studies, in which ARA and DHA were fed together in a 2:1 ratio ${ }^{(7-9)}$ ARA and DHA appear to compete for tissue incorporation, especially in the liver ${ }^{(10)}$ (C Tyburczy, KSD Kothapalli, W J Park, BS Blank, Y-C Liu, J M Nauroth, J P Zimmer, N Salem Jr and $\mathrm{J} T$ Brenna, unpublished results) and may influence each other's physiological effects ${ }^{(11,12)}$. The effect of this competition

Abbreviations: ARA, arachidonic acid; FA, fatty acids; FR, formula-reared; Hp, haptoglobin; hsCRP, high sensitivity C-reactive protein; LCPUFA, long-chain PUFA; MR, maternal-reared; SAA, serum amyloid A.

* Corresponding author: J. T. Brenna, email jtb4@cornell.edu 
on safety outcomes such as growth and immune function, particularly in the context of high ARA, remains unclear.

To date, there have been no ARA dose-response studies against a background of high dietary DHA in rapidly growing, suckling animals. The objective of the present study was to determine the effect of physiologically high dietary ARA on growth, clinical chemistry, haematology and immune function when DHA is constant and near the high end of human breast milk levels (i.e. $1.0 \mathrm{~g} / 100 \mathrm{~g}$ total FA). A dose-response for DHA was also included with normal levels of ARA. Domestic piglets were used because of their metabolic similarities to humans as well as the timing of perinatal brain growth ${ }^{(13)}$. Human breast milk is considered to be the 'gold standard' of nutrition for the developing infant, and because the FA composition and nutrient content of sow milk mimic human breast milk, an additional group of piglets were included as a maternal-reared (MR) reference treatment.

\section{Materials and methods}

\section{Animals}

The Cornell Center for Animal Resources and Education guidelines for the care and use of animals were followed, and all procedures involving animals were approved by the Institutional Animal Care and Use Committee at Cornell University, Ithaca, NY, USA (protocol no. 2010-0008). Domestic piglets were selected for sex and weight from fifteen sows at the swine facility at Cornell University. Pregnant sows were injected with $2 \mathrm{~cm}^{3}$ of Lutalyse (Pfizer Animal Health, Kalamazoo, MI, USA) 1 day before the scheduled, term farrowing date to obtain a block of piglets with the same birth date. Piglets were processed according to standard facility practices (i.e. intramuscular injection of $\mathrm{Fe}$ dextran (100 mg) and penicillin $\mathrm{G}\left(1 / 2 \mathrm{~cm}^{3}\right)$, tooth clip, tail dock, ear notch) and remained with the sow until day 3 of age, upon which they were matched for weight and assigned to one of six milk replacer diets ( $n$ 8). The formula-reared (FR) piglets were housed individually in raised metal cages and maintained on a $16 \mathrm{~h}$ light $-8 \mathrm{~h}$ dark cycle. MR piglets remained with their dam at the swine facility for the duration of the study.

\section{Diets}

Milk replacer formula consisting of $60 \mathrm{~g} / 100 \mathrm{~g}$ experimental diet (Research Diets, Inc., New Brunswick, NJ, USA) and $40 \mathrm{~g} / 100 \mathrm{~g}$ Birthright baby pig milk replacer (Ralco Nutrition, Inc., Marshall, MN, USA) was fed to FR piglets on days 3-28 of age. Diets were designed to meet or exceed the nutrient requirements for growing pigs $3-5 \mathrm{~kg}$ in body weight ${ }^{(14)}$. The nutrient composition of the Birthright baby pig milk replacer has been published elsewhere ${ }^{(15)}$. A detailed ingredient composition and nutrient analysis of the experimental diets are listed in Table 1. The four-oil blend consisting of palmolein, soya, coconut and high-oleic sunflower oils that is currently used in the commercial human infant formula Enfamil ${ }^{\circledR}$ (Mead-Johnson Nutrition, Evansville, IN, USA) made up the base oil for the experimental diets. LCPUFA were supplied by
Table 1. Ingredient composition and nutrient analysis of experimental diets

\begin{tabular}{lr}
\hline Composition & Content \\
\hline Dietary ingredient (\% DM) & \\
Dried skimmed milk & 55.0 \\
Oil blend & 23.9 \\
Calcium sodium caseinate & 9.6 \\
Mineral mix* & 4.8 \\
Vitamin mix & 4.8 \\
Xanthan gum & 1.4 \\
DL-Methionine & 0.5 \\
Nutrient analysis (\% kJ) & 24.3 \\
Protein & 28.7 \\
Carbohydrate & 47.0 \\
Fat & 19.6 \\
\hline
\end{tabular}

* The mineral mix contained the following $(\mathrm{g} / \mathrm{kg})$ : sucrose, 257.8 dibasic calcium phosphate, $615.8 ; \mathrm{NaCl}, 106.7$; ferric citrate, 11.8; zinc carbonate, 4.0; magnesium oxide, 3.4; cupric carbonate, 0.4 ; manganous carbonate, 0.2 ; potassium iodate, 0.1 ; sodium selenite, 0.01 .

† The vitamin mix contained the following $(\mathrm{g} / \mathrm{kg})$ : sucrose, $910 \cdot 1$ choline bitartrate, 75.0 ; vitamin $\mathrm{E}$ acetate $(50 \%), 6.2$; retinyl acetate $(172 \mu \mathrm{g} / \mathrm{mg}), 3.4$; cholecalciferol $(2.5 \mu \mathrm{g} / \mathrm{mg}), 1.5$; vitamin $B_{12}$ $(0.1 \%$ mannitol), 1.3 ; pantothenic acid $(\mathrm{D}, \mathrm{Ca}), 0.9$; niacin, 0.9 ; biotin $(1 \%), 0.4$; riboflavin, 0.1 ; thiamine $\mathrm{HCl}, 0.1$; menadione sodium bisulfite, 0.03 ; folic acid, 0.01 ; pyridoxine $\mathrm{HCl}, 0.01$.

DHASCO ${ }^{\circledR}$ and ARASCO ${ }^{\circledR}$ single-cell oils (Martek Biosciences, Inc., Columbia, MD, USA), derived from the micro-algae Crypthecodinium cohnii and the fungus Mortierella alpina, respectively. As fed, the milk replacer formula had an energy density of $2.93 \mathrm{~kJ} / \mathrm{ml}(0.7 \mathrm{kcal} / \mathrm{ml})$ and a macronutrient analysis as follows ( $\mathrm{g} \%$ ): protein, $27 \cdot 0$; fat, $22 \cdot 1$; carbohydrate, 39.5; fibre, $0 \cdot 7$; ash, $10 \cdot 7$. Formulas were reconstituted daily by adding 1.0 litre water to $180 \mathrm{~g}$ dry diet and stored at $3-4^{\circ} \mathrm{C}$ until feeding. Fresh formula was provided three times per $\mathrm{d}$ in stainless-steel bowls fixed into the cage doors, and ad libitum water was offered. FR piglets were fed at $80 \%$ ad libitum intake, based on pilot data, to moderately exceed growth rates of the MR piglets ${ }^{(16)}$. Formula intakes were recorded daily.

The FA composition of the milk replacer formula and sow milk (day 14 in lactation) is presented in Table 2. Diets varied in the ratio of ARA:DHA as follows ( $\mathrm{g} / 100 \mathrm{~g} \mathrm{FA} / \mathrm{FA})$ : A1, 0.1/1.0; A2, 0.53/1.0; A3-D3, 0.69/1.0; A4, 1.1/1.0; D2, $0 \cdot 67 / 0 \cdot 62$; D1, 0.66/0.33 (conventional infant formula), and corresponded to the following ARA:DHA intakes $(\mathrm{mg} / \mathrm{mg}$ per $418 \cdot 4 \mathrm{~kJ}$ (100 kcal) of formula): A1, 3.2/45.3; A2, 24.0/ 45.3; A3-D3, 31·3/45.3; A4, 49.0/45.3; D2, 30.4/28.1; D1, 29.9/14.9. Diets A1 to A 4 are a dose-response for ARA against DHA constant at $1.0 \mathrm{~g} / 100 \mathrm{~g}$, while diets D1 to D3 are a dose-response for DHA against ARA constant at $0.67 \mathrm{~g} / 100 \mathrm{~g}$. Diets D2 and A4 contain ARA and DHA at a 1:1 ratio, but at two different dietary levels, $0.67 \mathrm{~g} / 100 \mathrm{~g}$ and $1.0 \mathrm{~g} / 100 \mathrm{~g}$, respectively. The sow diets were a conventional pig ration consisting of maize and soyabean as $96 \%$ of the total dry weight. Our analysis showed that the PUFA were 18:2n-6 (53.9 (sD 0.2) g/100 g FA) and 18:3n-3 (3.4 (sD 0.1) g/100 g FA). The excess $18: 2$ and low $18: 3$ were probable factors in the very low sow milk DHA (0.01 (SD 0.01) g/100 g FA), 
Table 2. Fatty acid (FA) composition of milk replacer formulas and sow milk*

(Mean values and standard deviations)

\begin{tabular}{|c|c|c|c|c|c|c|c|c|}
\hline \multirow{2}{*}{$\begin{array}{l}\text { Treatment group } \\
\text { ARA/DHA }\end{array}$} & \multirow{2}{*}{$\begin{array}{c}A 1 \\
0 \cdot 1 / 1 \cdot 0\end{array}$} & \multirow{2}{*}{$\begin{array}{c}A 2 \\
0.53 / 1.0\end{array}$} & \multirow{2}{*}{$\begin{array}{l}\text { A3-D3 } \\
0.69 / 1 \cdot 0\end{array}$} & \multirow{2}{*}{$\begin{array}{c}\text { A4 } \\
1 \cdot 1 / 1 \cdot 0\end{array}$} & \multirow{2}{*}{$\begin{array}{c}D 2 \\
0.67 / 0.62\end{array}$} & \multirow{2}{*}{$\begin{array}{c}D 1 \\
0.66 / 0.33\end{array}$} & \multicolumn{2}{|c|}{$\begin{array}{c}\text { MR } \\
0.74 / 0.01\end{array}$} \\
\hline & & & & & & & Mean & SD \\
\hline \multicolumn{9}{|l|}{$\mathrm{FA}(\mathrm{g} / 100 \mathrm{~g}$ total $\mathrm{FA})$} \\
\hline$\Sigma S F A+M U F A$ & $79 \cdot 86$ & 79.94 & $79 \cdot 43$ & $79 \cdot 18$ & $80 \cdot 02$ & $80 \cdot 02$ & 83.94 & $3 \cdot 16$ \\
\hline ARA & 0.09 & 0.53 & 0.69 & 1.06 & 0.67 & 0.66 & 0.74 & 0.02 \\
\hline DHA & 1.00 & 1.02 & 1.01 & 1.04 & 0.62 & 0.33 & 0.01 & 0.01 \\
\hline$\sum n-6$ & $17 \cdot 50$ & $17 \cdot 52$ & 17.95 & $18 \cdot 15$ & $17 \cdot 76$ & $18 \cdot 00$ & $15 \cdot 21$ & 3.08 \\
\hline$\sum n-3$ & 2.53 & 2.43 & 2.49 & $2 \cdot 51$ & $2 \cdot 10$ & 1.86 & 0.71 & 0.04 \\
\hline $18: 2 n-6$ & $17 \cdot 25$ & $16 \cdot 83$ & $17 \cdot 11$ & 16.93 & 16.90 & $17 \cdot 19$ & $12 \cdot 05$ & 2.98 \\
\hline $18: 3 n-3$ & 1.53 & 1.41 & 1.48 & 1.47 & 1.48 & 1.53 & 0.57 & 0.06 \\
\hline $18: 2 n-6 / 18: 3 n-3$ & $11 \cdot 3$ & $12 \cdot 0$ & 11.6 & 11.5 & 11.4 & $11 \cdot 3$ & \multicolumn{2}{|c|}{$21 \cdot 1$} \\
\hline
\end{tabular}

ARA, arachidonic acid; MR, maternal-reared.

* Milk from two sows taken on day 14 of lactation; MR piglets remained with the sow for the duration of the study. The PUFA content of sow diets during gestation and lactation consisted of $18: 2 n-6(53.90$ (SD 0.17) g/100 g FA) and 18:3n-3 (3.44 (SD 0.04) g/100 g FA) as the sole source of $n-3$ PUFA.

while ARA was towards the upper end of the human milk range $(0.74$ (SD 0.02) g/100 g FA).

FA composition of the diets and sow milk was determined by GC. FA methyl esters were prepared from dry diet and $50 \mu \mathrm{l}$ sow milk by the one-step hydrolysis, extraction and methylation procedure ${ }^{(17)}$ as modified previously ${ }^{(18)}$, and quantified on a 5890 Series II gas chromatograph (HewlettPackard, Palo Alto, CA, USA) equipped with a BPX70 fused silica column $(25 \mathrm{~m} \times 0.22 \mathrm{~mm}$ inner diameter $\times 0.25 \mu \mathrm{m}$ film; SGE, Inc., Austin, TX, USA). An equal weight FA methyl ester mixture was used to verify response factors. FA methyl esters were structurally identified by covalent-adduct chemical ionisation tandem MS on a Saturn 2000 ion trap mass spectrometer (Varian, Inc., Walnut Creek, CA, USA) ${ }^{(19)}$.

\section{Sampling}

Body weight measurements were taken weekly. Non-fasted blood samples were collected from the anterior vena cava into vacutainer tubes (Becton Dickinson \& Company, Franklin Lakes, NJ, USA) on days 3, 7, 14 and 21 of age. Overnightfasted blood samples were collected on day 28 of age, and an additional aliquot of blood was collected into EDTAcontaining tubes for haematological analysis. Serum was harvested by centrifuging clotted blood at $2800 \mathrm{rpm}$ and $4^{\circ} \mathrm{C}$ for $10 \mathrm{~min}$. Piglets were killed on day 28 of age via an intravenous injection of Fatal Plus ( $1 \mathrm{ml} / 4.54 \mathrm{~kg}$ body weight; Vortech Pharmaceuticals, Dearborn, MI, USA) followed by exsanguination. Organs were removed and weighed, and samples were flash frozen within $10 \mathrm{~min}$ of cessation of heart beat.

\section{Clinical chemistry and haematological analysis}

Serum and blood obtained from 28-d-old piglets were delivered promptly to the Animal Health Diagnostic Center (College of Veterinary Medicine, Cornell University) for analysis of clinical chemistry and haematological parameters.

\section{Mycoplasma hyopneumoniae vaccination}

Piglets were vaccinated against Mycoplasma byopneumoniae (RespiSure-One ${ }^{\circledR}$; Pfizer Animal Health) on day 7 of age. Serum samples collected on days 21 and 28 of age (14 and $21 \mathrm{~d}$ post-immunisation) were analysed for antibodies to M. byopneumoniae. M. byopneumoniae immunity protects against a common respiratory disease in swine that is not endemic at the Cornell University swine facility or the Large Animal Research and Teaching Unit. RespiSure-One ${ }^{\circledR}$ is intended to induce a protective antibody titre $14-21 \mathrm{~d}$ after a single injection at day $7^{(20,21)}$.

\section{ELISA}

Serum samples were thawed immediately before use. Commercial ELISA kits were used to quantify serum total IgA, IgG and IgM (Bethyl Laboratories, Montgomery, TX, USA) and the acute-phase proteins high sensitivity C-reactive protein (hsCRP) and haptoglobin (Hp) (Kamiya Biomedical Company, Seattle, WA, USA), and serum amyloid A (SAA) (Tri-Delta Development Limited, Bray, Ireland) following the manufacturer's instructions. Antibodies to M. byopneumoniae were detected by semi-quantitative ELISA following the manufacturer's instructions (HerdChek ${ }^{\mathrm{TM}}$; IDEXX Laboratories, Westbrook, ME, USA). Serum samples were tested in duplicate, with the exception of the Hp ELISA, in which two different serum dilutions (1:10 000 and 1:20000) were averaged.

\section{Statistical analysis}

Statistical analysis was carried out using the Fit Model platform of JMP (version 8.0; SAS Institute, Inc., Cary, NC, USA, 2008) to fit mixed models. Fixed effects were diet, sex, body weight at day 3 of age and the full factorial of interactions. Interaction effects were considered significant at $P<0 \cdot 10$ and fixed effects at $P<0 \cdot 05$. For each parameter analysed, effects that were not considered significant were removed in a stepwise manner from the final model. Random effects were litter and animal nested within litter for repeated measures of body weight. 

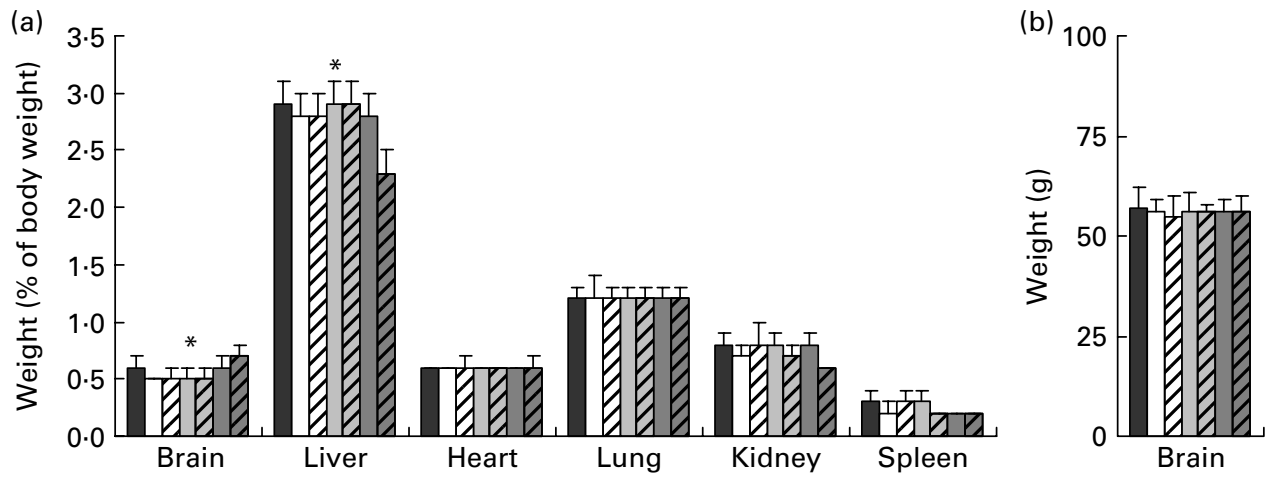

Fig. 1. (a) Relative organ and (b) absolute brain weights taken on day 28 of age from piglets fed varying levels of arachidonic acid (ARA) and DHA. Dietary con-

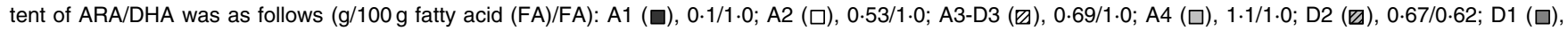
$0.66 / 0.33$. Values are means, with standard deviations represented by vertical bars. * Mean values were significantly different between maternal-reared $(\square)$ piglets and all formula-reared groups $(P<0.001)$.

Significance of pairwise comparisons was determined using the Student's $t$ test. Linear regression analysis was performed to determine the relationship between clinical chemistry and haematological parameters and the dietary content of ARA and DHA. Values are reported as means and standard deviations.

\section{Results}

\section{Clinical observations, feed intake and growth}

All fifty-six piglets remained in the study until day 28 of age, and only one piglet (group A3-D3) required antibiotic treatment during the study, which was due to developing an abscess on its toe. Total formula intakes averaged 51.6 (SD $0 \cdot 1$ ) litres and were unaffected by the diet. There were small differences in body weight among the FR groups on day 7 of age, with group A1 piglets (ARA/DHA, 0.1/1.0) weighing $3 \%$ less than all other FR groups (2.6 (SD 0.3) $v$. 2.7 (SD 0.2$) \mathrm{kg}$, respectively; $P<0.01$ ). By day 14 of age, this difference in body weight had disappeared, and the group A1 piglets proceeded to grow as well as all other FR groups for the remainder of the study. Furthermore, there were no differences in body weight among any of the FR groups on days 14, 21 or 28 of age. The MR group was heavier than the FR groups on day 7 of age $(P<0.001)$, but the MR group weighed the least at days 21 and 28 of age $(P<0 \cdot 0001)$. On day 28 of age, mean weight for all FR piglets was $10 \cdot 3$ (SD 0.6) kg, while MR piglets weighed 7.9 (SD 0.7) kg.

Relative organ weights (weight as a percentage of final body weight) from piglets on day 28 of age are presented in Fig. 1(a). There were no differences in relative organ weights among any of the FR groups; however, compared with the MR group, the FR piglets had greater relative weights for the liver $(P<0.001)$. Absolute brain weights (Fig. 1(b)) were similar across all diets, while relative brain weight was greatest for the MR piglets compared with the FR groups $(P<0 \cdot 001)$.

\section{Haematology and clinical chemistry parameters}

Data for the haematological analysis are presented in Fig. 2. Small differences were apparent among the FR groups for mean cell $\mathrm{Hb}$ and red cell distribution width. There were no differences among the FR groups for $\mathrm{Hb}$, mean cell $\mathrm{Hb}$ concentration and mean cell volume; however, the FR groups significantly differed from the MR piglets for these values, with the MR group presenting a more favourable haematological status. Mean values for haematocrit and erythrocytes count were $35(\mathrm{SD} 4) \%$ and $6.7(\mathrm{SD} 0.6) 10^{6} / \mu \mathrm{l}$, respectively, and

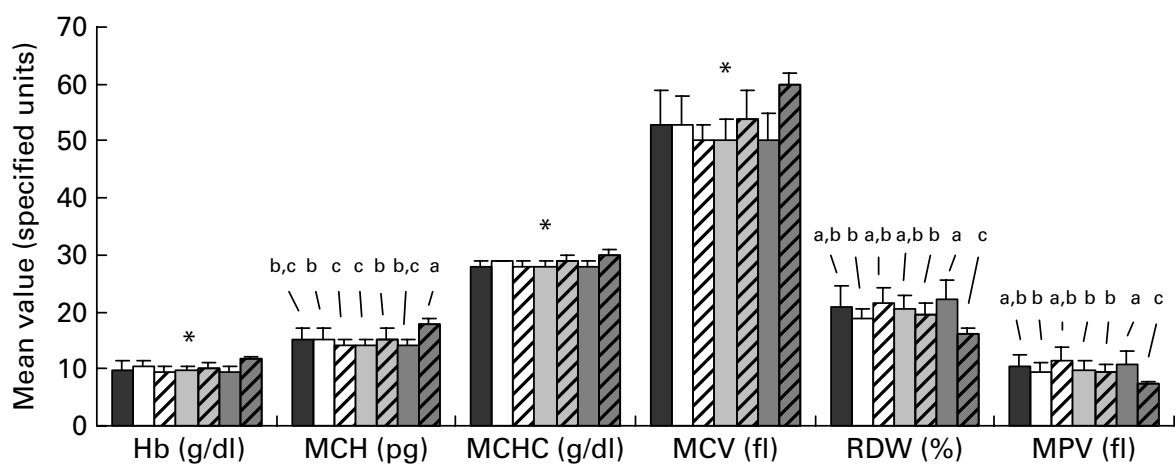

Fig. 2. Profile of selected haematological parameters taken on day 28 of age from piglets fed varying levels of arachidonic acid (ARA) and DHA. Dietary content

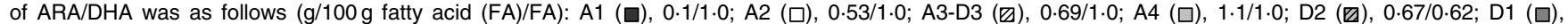
$0.66 / 0.33$. Values are means, with standard deviations represented by vertical bars. ${ }^{\mathrm{a}, \mathrm{b}, \mathrm{c}}$ Mean values with unlike letters were significantly different $(P<0.05)$; ${ }^{*}$ Mean values were significantly different between maternal-reared $(\approx)$ piglets and all formula-reared groups $(P<0.05)$. $\mathrm{MCH}, \mathrm{mean} \mathrm{Cell} \mathrm{Hb}$; $\mathrm{MCHC}$, mean cell $\mathrm{Hb}$ concentration; MCV, mean cell volume; RDW, red cell distribution width; MPV, mean platelet volume. 
Table 3. Summary of clinical chemistry profiles taken on day 28 of age from piglets fed varying levels of arachidonic acid (ARA) and DHA

(Mean values and standard deviations, $n 8$ )

\begin{tabular}{|c|c|c|c|c|c|c|c|c|c|c|c|c|c|c|c|}
\hline \multirow{2}{*}{$\begin{array}{l}\text { Treatment group } \\
\text { ARA/DHA } \\
(\mathrm{g} / 100 \mathrm{~g}, \mathrm{FA} / \mathrm{FA})\end{array}$} & \multicolumn{2}{|c|}{$\begin{array}{c}\text { A1 } \\
0.09 / 1.00\end{array}$} & \multicolumn{2}{|c|}{$\begin{array}{c}\text { A2 } \\
0.53 / 1.02\end{array}$} & \multicolumn{2}{|c|}{$\begin{array}{c}\text { A3-D3 } \\
0.69 / 1.01\end{array}$} & \multicolumn{2}{|c|}{$\begin{array}{c}\text { A4 } \\
1.06 / 1.04\end{array}$} & \multicolumn{2}{|c|}{$\begin{array}{c}\text { D2 } \\
0.67 / 0.62\end{array}$} & \multicolumn{2}{|c|}{$\begin{array}{c}D 1 \\
0.66 / 0.33\end{array}$} & \multicolumn{2}{|c|}{$\begin{array}{c}\text { MR } \\
0.74 / 0.01\end{array}$} & \multirow[b]{2}{*}{$P$} \\
\hline & Mean & SD & Mean & SD & Mean & SD & Mean & SD & Mean & SD & Mean & SD & Mean & SD & \\
\hline Glucose (mmol/l) & $8 \cdot 7$ & 1.7 & $8 \cdot 4$ & 1.8 & $8 \cdot 8$ & 1.5 & $8 \cdot 7$ & 1.8 & $9 \cdot 0$ & 1.5 & $9 \cdot 4$ & 1.8 & $7 \cdot 3$ & 0.4 & $\mathrm{NS}^{*}$ \\
\hline BUN (mmol/l) & $2 \cdot 2$ & 0.4 & $2 \cdot 2$ & 0.7 & $2 \cdot 0$ & 0.5 & $2 \cdot 2$ & 0.6 & $2 \cdot 1$ & 0.4 & $2 \cdot 3$ & 0.7 & $2 \cdot 7$ & 0.4 & $\mathrm{NS}^{*}$ \\
\hline Creatinine $(\mu \mathrm{mol} / \mathrm{l})$ & 65 & 8 & 70 & 9 & 64 & 12 & 71 & 9 & 66 & 12 & 73 & 8 & 77 & 9 & $\mathrm{NS}^{*}$ \\
\hline Total protein $(\mathrm{g} / \mathrm{l})$ & 52 & 3 & 50 & 3 & 50 & 3 & 51 & 4 & 50 & 3 & 53 & 3 & 47 & 3 & $\mathrm{NS}^{*}$ \\
\hline Total bilirubin $(\mu \mathrm{mol} / \mathrm{l})$ & $1 \cdot 7$ & 0.9 & $2 \cdot 4$ & 0.3 & $2 \cdot 8$ & 0.9 & $2 \cdot 1$ & 1.2 & 1.9 & $1 \cdot 1$ & $2 \cdot 1$ & 1.2 & $2 \cdot 8$ & $2 \cdot 6$ & $N S^{*}$ \\
\hline $\mathrm{Na}(\mathrm{mmol} / \mathrm{l})$ & 143 & 4 & 143 & 3 & 144 & 3 & 145 & 3 & 143 & 2 & 144 & 2 & 141 & 2 & $\mathrm{NS}^{*}$ \\
\hline $\mathrm{K}(\mathrm{mmol} / \mathrm{l})$ & 5.9 & 0.7 & $6 \cdot 2$ & 0.7 & $6 \cdot 2$ & 0.8 & $6 \cdot 2$ & 0.8 & $5 \cdot 9$ & 0.8 & 5.9 & 0.5 & $5 \cdot 2$ & 0.9 & $N S^{*}$ \\
\hline $\mathrm{Cl}(\mathrm{mmol} / \mathrm{l})$ & $100^{c}$ & 2 & $101^{\mathrm{b}, \mathrm{c}}$ & 1 & $102^{a, b}$ & 2 & $101^{a, b}$ & 2 & $100^{\mathrm{b}, \mathrm{c}}$ & 2 & $100^{c}$ & 2 & $105^{\mathrm{a}}$ & 2 & 0.02 \\
\hline Bicarbonate $(\mathrm{mmol} / \mathrm{l})$ & 19 & 5 & 21 & 5 & 20 & 4 & 20 & 6 & 21 & 4 & 19 & 5 & 23 & 2 & $\mathrm{NS}^{*}$ \\
\hline $\mathrm{Ca}(\mathrm{mmol} / \mathrm{l})$ & $2 \cdot 8$ & 0.2 & $2 \cdot 8$ & 0.2 & $2 \cdot 8$ & 0.1 & $2 \cdot 8$ & 0.2 & $2 \cdot 8$ & 0.1 & $2 \cdot 8$ & 0.1 & $2 \cdot 6$ & 0.1 & $\mathrm{NS}^{*}$ \\
\hline $\mathrm{P}(\mathrm{mmol} / \mathrm{l})$ & $3 \cdot 5^{\mathrm{a}}$ & 0.3 & $3 \cdot 6^{a}$ & 0.3 & $3 \cdot 6^{a}$ & 0.3 & $3 \cdot 5^{\mathrm{a}}$ & 0.3 & $3 \cdot 6^{\mathrm{a}}$ & 0.3 & $3 \cdot 5^{\mathrm{a}}$ & 0.2 & $2 \cdot 6^{\mathrm{b}}$ & 0.2 & $<0.0001$ \\
\hline $\mathrm{Mg}(\mathrm{mmol} / \mathrm{l})$ & 0.9 & 0.1 & 0.9 & $0 \cdot 1$ & 0.9 & $0 \cdot 1$ & $1 \cdot 0$ & $0 \cdot 1$ & 1.0 & 0.2 & $1 \cdot 0$ & $0 \cdot 1$ & $1 \cdot 0$ & $0 \cdot 1$ & $N S^{*}$ \\
\hline $\mathrm{Fe}(\mu \mathrm{mol} / \mathrm{l})$ & $4.0^{\mathrm{b}}$ & 1.4 & $4 \cdot 4^{b}$ & 1.6 & $3 \cdot 2^{b}$ & 0.4 & $4 \cdot 2^{b}$ & 1.2 & $4 \cdot 0^{\mathrm{b}}$ & 0.7 & 7.4 & $9 \cdot 0^{\mathrm{b}}$ & $16 \cdot 2^{\mathrm{a}}$ & $7 \cdot 2$ & $<0.0001$ \\
\hline TIBC $(\mu \mathrm{mol} / \mathrm{l})$ & $146^{a}$ & 10 & $137^{\mathrm{a}}$ & 12 & $146^{\mathrm{a}}$ & 15 & $144^{\mathrm{a}}$ & 14 & $138^{\mathrm{a}}$ & 11 & $143^{a}$ & 18 & $71^{\mathrm{b}}$ & 9 & $<0.0001$ \\
\hline Saturation (\%) & $3^{\mathrm{b}}$ & 1 & $4^{\mathrm{b}}$ & 1 & $2^{b}$ & 0 & $3^{b}$ & 1 & $3^{\mathrm{b}}$ & 1 & $6^{b}$ & 7 & $23^{a}$ & 10 & $<0.0001$ \\
\hline Albumin (g/l) & $41^{\mathrm{a}, \mathrm{b}}$ & 2 & $41^{a, b}$ & 2 & $40^{\mathrm{b}}$ & 3 & $41^{\mathrm{a}, \mathrm{b}}$ & 3 & $40^{a, b}$ & 2 & $43^{\mathrm{a}}$ & 2 & $34^{\mathrm{c}}$ & 3 & 0.0002 \\
\hline Globulin (g/l) & $11^{\mathrm{a}}$ & 3 & $10^{c}$ & 2 & $10^{\mathrm{a}, \mathrm{b}, \mathrm{c}}$ & 2 & $10^{\mathrm{a}, \mathrm{b}, \mathrm{c}}$ & 2 & $10^{\mathrm{b}, \mathrm{c}}$ & 2 & $10^{\mathrm{a}}$ & 2 & $13^{\mathrm{a}, \mathrm{b}, \mathrm{c}}$ & 4 & 0.02 \\
\hline Albumin/globulin & $4 \cdot 1$ & $1 \cdot 2$ & 4.4 & $1 \cdot 0$ & $4 \cdot 2$ & $1 \cdot 1$ & $4 \cdot 2$ & 0.6 & 4.4 & 0.9 & $4 \cdot 3$ & 0.8 & $2 \cdot 9$ & 1.0 & $\mathrm{NS}^{*}$ \\
\hline
\end{tabular}

MR, maternal-reared; FA, fatty acid; BUN, blood urea nitrogen; TIBC, total Fe binding capacity.

a,b,c Mean values within a row with unlike superscript letters were significantly different $(P<0.05)$.

${ }^{*}$ Mean values were not significantly different $(P>0.05)$.

were unaffected by diet. For all piglets, platelet count averaged $1022(\mathrm{SD} 259) 10^{3} / \mu \mathrm{l}$ and was unaffected by treatment.

Total leucocytes count averaged $9 \cdot 8$ (SD 3.3) $10^{3} / \mu$ l and was unaffected by diet. There were no differences among diets for segmented neutrophils, monocytes, eosinophils or basophils (data not presented). Lymphocyte count was highest in group A4 piglets; however, the range of means $(4 \cdot 9-6 \cdot 8) 10^{3} / \mu \mathrm{l}$ across all diets was within the normal reference range for nursery piglets ${ }^{(22)}$.

Consistent with the haematological analysis, only small differences in the clinical chemistry profile were apparent among the FR groups, including values for serum chloride, phosphorous, albumin and globulin, as listed in Table 3 . While statistical differences were observed for these parameters, values fall within the normal reference ranges for nursery piglets $^{(23,24)}$ and thus were likely to be biologically insignificant. Also consistent with the haematological analysis, clinical chemistry values related to serum Fe status (i.e. serum $\mathrm{Fe}$, total Fe binding capacity and percentage saturation) were different between MR and FR groups, and indicated a more positive serum Fe status for the MR piglets. Additional serum clinical chemistry parameters that were not significantly different among any of the dietary treatments were creatinine, aspartate aminotransferase, glutamate dehydrogenase, alkaline phosphatase, $\gamma$-glutamyl transferase, sorbitol dehydrogenase and creatinine kinase.

\section{Immunisation response and measurements of immune status}

All piglets were negative for antibodies to $M$. byopneumoniae on day 28 of age. There were no significant differences in titres to $M$. byopneumoniae by dietary treatment, with mean relative levels among all piglets being $0 \cdot 1$ (SD 0.1) sample/ positive. On day 28 of age, serum IgA levels in the MR piglets (408 (sD 99) $\mu \mathrm{g} / \mathrm{ml}$ ) were significantly higher than all FR groups (158 (SD 69) $\mu \mathrm{g} / \mathrm{ml} ; P<0 \cdot 001$ ); IgA levels were similar among the FR groups. Serum IgM and IgG levels on day 28 of age were unaffected by diet, and averaged 553 (SD 218) and 4782 (SD 1047) $\mu \mathrm{g} / \mathrm{ml}$, respectively, for pooled mean and standard deviation of all piglets in all groups ( $n$ 56) SAA levels were unaffected by diet on day 3 and 28 of age. SAA levels on day 28 of age averaged 2.7 (SD 3.4) $\mu \mathrm{g} / \mathrm{ml}$ for all piglets. There were, however, minor differences in SAA levels on day 7 of age, with group A1 (17.0 (SD 29.0) $\mu \mathrm{g} / \mathrm{ml})$ having significantly higher levels than most other groups $(P<0 \cdot 05)$. Similarly, there were minor, statistically significant differences in serum Hp levels among the FR groups on day 28, although no discernable pattern among diets was apparent. Hp in the MR piglets was below detectable limits. Serum hsCRP levels were similar among all groups on days 3, 7, 14, 21 and 28 of age, and averaged 13.6 (SD 5.3) $\mu \mathrm{g} / \mathrm{ml}$ among dietary treatment groups on day 28 .

\section{Discussion}

There is broad consensus that human milk composition serves as a model for infant formula. All breast milk naturally contains ARA and DHA, but the range of reported concentrations is wide, and thus studies of optimal levels within the natural range are relevant to setting composition guidelines. With interest in optimising the formula content of ARA and DHA for proper development of the infant central nervous and immune systems, it is critical to determine the interaction between these two LCPUFA and their resulting effect on growth and development. The present study was carried out 
to determine whether ARA near the upper end of human breast milk levels and with constant, high DHA influences various parameters associated with growth and immune functions.

Human term and pre-term infants are capable of synthesising ARA and DHA from the dietary precursors linoleic acid (18:2n-6) and $\alpha$-linolenic acid (18:3n-3), respectively ${ }^{(25)}$, although the rates of endogenous DHA biosynthesis are insufficient to support optimal neural and visual development in the Western countries in which studies have been conducted $^{(26)}$. Formulas supplemented with single-cell TAG oils act as highly bioavailable sources of LCPUFA and enhance the plasma and erythrocyte content of ARA and DHA compared with infants consuming LCPUFA-free formula, and within the range of breast-fed infants ${ }^{(27)}$. However, plasma and erythrocyte ARA levels serve as surrogate biomarkers for tissue status, especially with regard to neural tissue ${ }^{(28)}$. Safety and functional outcome studies are thus necessary to develop a complete picture of the relationship between LCPUFA intake and overall health and development.

Growth is among the most useful clinical markers of infant development. Over the last two decades, growth has been implicated as a basis for addition of ARA to infant formula. Early studies showed a correlation between blood ARA and growth in pre-term infants fed formula supplemented with marine oil ${ }^{(29)}$, and prompted investigation of the hypothesis that plasma ARA levels are crucial to growth outcomes ${ }^{(30)}$. Recent studies, however, indicate that LCPUFA supplementation has a negligible effect on growth ${ }^{(4,5)}$. In the present study, piglets fed $0 \cdot 1 \mathrm{~g} / 100 \mathrm{~g}$ ARA had marginally lower body weights only on day 7 of age compared with all other FR and MR piglets. These differences in body weight disappeared by day 14 of age and the $0 \cdot 1 \mathrm{~g} / 100 \mathrm{~g}$ ARA piglets grew as well as all other FR pigs for the remainder of the study. Neonatal piglets grow approximately eightfold faster than human infants during the first 2 weeks of life $\mathrm{e}^{(31)}$, with correspondingly greater intake. The consequences of nutritional deficiency are exaggerated in piglets, and any effects of dietary ARA on growth should be amplified. At most a marginal, transient effect of low ARA was observed in the present study. We conclude that the dietary ARA level has a negligible effect on growth outcomes, consistent with the recent reports in human infants ${ }^{(4,5)}$.

The absence or presence of DHA and ARA in piglet formula can modulate neonatal immune responses ${ }^{(32)}$. In the present study, three immune status measures were included to examine immunisation response, immune maturation and inflammatory state. These measures enable piglet data to be applied to infants. First, if the dietary treatments modulated the immunisation response in the piglets, then clinical trials could follow up by monitoring vaccine responses in infants. For immune maturation, it is known that early-life serum IgA and $\operatorname{IgG}$ concentrations increase as exogenous antigen exposures accumulate ${ }^{(33)}$. This applies to piglets as well because gnotobiotic pigs have significantly lower serum IgA and IgG compared with conventionally raised pigs with a typical gut microflora ${ }^{(34)}$. Thus, serum IgA or IgG may provide a novel but rough comparison of net immunological maturation across dietary treatments. Finally, higher intakes of DHA are anti-inflammatory in humans and animal models ${ }^{(35)}$, but it is not known whether increasing the dietary ratio of ARA:DHA in piglet formula produces a pro-inflammatory state. A wide range of clinical and subclinical inflammatory events can trigger the liver to produce serum acute-phase proteins. Thus we monitored three different acute-phase proteins, hsCRP, SAA and $\mathrm{Hp}$, because they can differ in their sensitivity to detect systemic inflammation $^{(36)}$.

M. byopneumoniae titres did not differ among any of the dietary treatment groups. Titres were also relatively low compared with the manufacturer's data on RespiSure-One ${ }^{\circledR(20,21)}$. The HerdChek ELISA kit is intended to monitor pig herds for outbreaks of $M$. byopneumoniae and focuses on dividing sample titres into positive $v$. negative cases relative to a single positive control sample, and may have limited ability to detect subtle changes. Future studies using this system may benefit from different immunisations or immunisation schedules to induce higher serum titres and a detection test with a broader dose-response curve.

MR piglets had significantly higher levels of serum IgA than the other dietary treatment groups. One possible explanation is that some or all of the IgA is maternally derived. However, by $24-36 \mathrm{~h}$ after birth, piglets no longer transport milk Ig from the gut into circulation ${ }^{(37)}$. And, based on ${ }^{125}$ I labelled Ig clearance rates ${ }^{(38)}$, the average half-life of maternally-derived IgA is $2 \cdot 7 \mathrm{~d}$. Thus, the elevated IgA in the serum of MR pigs is unlikely to be of maternal origin and may reflect differences in the rate of maturation. Both serum IgG and IgM showed groupwise comparison trends similar to IgA but failed to reach significance. The lack of significant differences among the FR groups indicates that altering the dietary amounts or ratios of ARA to DHA has no adverse effect on immunological maturation.

Serum acute-phase protein levels showed few significant differences among any of the dietary treatment groups. Values were highly variable, especially for $\mathrm{Hp}$ and SAA, and had inconsistent patterns of between-group differences. SAA levels were slightly higher than values for our MR pigs but showed a similar trend of decreasing levels with age ${ }^{(39)}$. In the present study, where significant differences were found among dietary treatment groups, e.g. day $28 \mathrm{Hp}$ and day 7 SAA, they were not associated with higher concentrations of ARA relative to DHA. Furthermore, hsCRP levels were similar among all dietary ARA groups (A1-A4) at every time point measured. Thus, from the battery of three acute-phase protein tests, we could not find evidence that increasing ARA relative to DHA produces a detectable pro-inflammatory state.

A superficially striking observation from the present study was the large difference in growth, haematology and clinical chemistry parameters between the MR and FR piglets. These results were not unexpected, however, as the diet and rearing environment differed tremendously between the two groups. In terms of growth, we opted to set intakes for the FR piglets at $80 \%$ ad libitum intake based on reports of growth patterns for MR piglets ${ }^{(16)}$ and data from a pilot study. This would enable a moderately faster rate of growth for the FR piglets, which was observed with a $2 \mathrm{~kg}$ difference in body weight 
between FR and MR piglets on day 28 of age. Remarkably, absolute brain weights were unaffected by diet. However, relative brain weights expressed as brain weight as a percentage of body weight were greatest for the MR piglets, and driven entirely by the larger carcasses of the FR groups. Here, excess nutrients beyond those required for brain growth were partitioned to the FR carcass, highlighting the brain's protected growth during the perinatal period. Differences between the MR piglets and the FR groups were also observed for biomarkers of blood $\mathrm{Fe}$ status, including $\mathrm{Hb}$, serum Fe, total Fe binding capacity and percentage saturation. Furugouri $^{(40)}$ demonstrated that rapidly growing piglets exhibit high levels of erythropoiesis and have a heightened daily requirement for available Fe. In the present study, the faster rates of growth observed for the FR piglets compared with the MR group corresponded to a heightened demand for $\mathrm{Fe}$ that was apparently unmet and manifested as poorer blood Fe status.

We have previously examined the safety of ARA and DHA ᄃ for use in formula at $0,1,2$ and 5 times the levels currently used in conventional infant formulas ${ }^{(8)}$. For the $5 \times$ diet, levels of ARA and DHA corresponded to 3.15 and $1.66 \mathrm{~g} / 100 \mathrm{~g}$ total FA, respectively, and across the full range of ARA and DHA intakes tested, no untoward effects were observed for growth, clinical chemistry or liver histopathology. Others have observed a similar negligible effect on growth outcomes when ARA and DHA were fed three times the level in conventional formulas ${ }^{(9)}$. Questions related to the possible influence of different ratios of ARA and DHA on growth and immune function led us to conduct the present study. We observed negligible differences among all the FR groups, indicating that the dietary ARA level, when DHA is constant at $1.0 \mathrm{~g} / 100 \mathrm{~g}$ total FA, does not influence the outcomes measured here in the neonatal period.

In these piglets, ARA levels in the heart and liver were responsive to dietary ARA intake, while ARA levels in the brain and retina were not (C. Tyburczy, K. S. D. Kothapalli, W. J. Park, B. S. Blank, Y.-C. Liu, J. M. Nauroth, J. P. Zimmer, N. Salem Jr, J. T. Brenna, unpublished results). The heart showed strong sensitivity to the dietary ARA level, with accretion being limited by dietary supply. Whether these compositional changes in tissue ARA content are associated with the health and well-being of the developing infant remain to be investigated.

In conclusion, milk replacer formulas supplemented with physiologically high levels of ARA and DHA supported normal growth, development and immune function in rapidly growing domestic piglets up to $28 \mathrm{~d}$ of age. Dietary ARA level comprising $0 \cdot 1-1 \cdot 0 \mathrm{~g} / 100 \mathrm{~g}$ total FA and fed concomitantly with $1.0 \mathrm{~g} / 100 \mathrm{~g}$ DHA produced no adverse effects in any of the clinical chemistry, haematology or immune function parameters that were measured.

\section{Acknowledgements}

The present study was supported by Martek Biosciences Corporation (Columbia, MD, USA) and DSM Food Specialties (Delft, The Netherlands). Mead Johnson Nutrition (Evansville,
IN, USA) provided base fat for the experimental diets. The present study was supported in part by Award T32DK007158 from the National Institute of Diabetes and Digestive and Kidney Diseases of the National Institutes of Health. The content is solely the responsibility of the authors and does not necessarily represent the official views of the National Institutes of Health. The authors are grateful for the technical assistance of Lisa Furman, Peter Lawrence and Karl Roneker (Cornell University). J. T. B., N. S. and J. P. Z. designed the study; B. S. B., K. S. D. K., Y.-C. L., J. M. N., W. J. P. and C. T. conducted the study; Y.-C. L., J. M. N. and C. T. analysed the data; J. T. B., Y.-C. L., J. M. N., C. T. and J. P. Z. wrote the manuscript. N. S., Y.-C. L. and J. M. N. are employees of Martek Biosciences Corporation; B. S. B, J. T. B, K. S. D. K., W. J. P., C. T. and J. P. Z. report no conflicts of interest.

\section{References}

1. Calder PC, Krauss-Etschmann S, de Jong EC, et al. (2006) Early nutrition and immunity - progress and perspectives. Br J Nutr 96, 774-790.

2. FAO/WHO (1994) Fats and Oils in Human Nutrition. Report of a Joint Expert Consultation. FAO Food and Nutrition Paper no. 57, pp. 49-55. Rome: FAO/WHO.

3. Brenna JT, Varamini B, Jensen RG, et al. (2007) Docosahexaenoic and arachidonic acid concentrations in human breast milk worldwide. Am J Clin Nutr 85, 1457-1464.

4. Makrides M, Gibson RA, Udell T, et al. (2005) Supplementation of infant formula with long-chain polyunsaturated fatty acids does not influence the growth of term infants. Am J Clin Nutr 81, 1094-1101.

5. Rosenfeld E, Beyerlein A, Hadders-Algra M, et al. (2009) IPD meta-analysis shows no effect of LC-PUFA supplementation on infant growth at 18 months. Acta Paediatr 98, 91-97.

6. Hoffman DR, Boettcher JA \& Diersen-Schade DA (2009) Toward optimizing vision and cognition in term infants by dietary docosahexaenoic and arachidonic acid supplementation: a review of randomized controlled trials. Prostaglandins Leukot Essent Fatty Acids 81, 151-158.

7. Boswell K, Koskelo EK, Carl L, et al. (1996) Preclinical evaluation of single-cell oils that are highly enriched with arachidonic acid and docosahexaenoic acid. Food Chem Toxicol 34, 585-593.

8. Huang MC, Chao A, Kirwan R, et al. (2002) Negligible changes in piglet serum clinical indicators or organ weights due to dietary single-cell long-chain polyunsaturated oils. Food Chem Toxicol 40, 453-460.

9. Merritt RJ, Auestad N, Kruger C, et al. (2003) Safety evaluation of sources of docosahexaenoic acid and arachidonic acid for use in infant formulas in newborn piglets. Food Chem Toxicol 41, 897-904.

10. Hsieh AT, Anthony JC, Diersen-Schade DA, et al. (2007) The influence of moderate and high dietary long chain polyunsaturated fatty acids (LCPUFA) on baboon neonate tissue fatty acids. Pediatr Res 61, 537-545.

11. Rapoport SI \& Bosetti F (2002) Do lithium and anticonvulsants target the brain arachidonic acid cascade in bipolar disorder? Arch Gen Psychiatry 59, 592-596.

12. Calder PC (2009) Polyunsaturated fatty acids and inflammatory processes: new twists in an old tale. Biochimie 91, 791-795.

13. Dobbing J \& Sands J (1979) Comparative aspects of the brain growth spurt. Early Hum Dev 3, 79-83. 
14. National Research Council (1998) Nutrient Requirements of Swine: 10th revised ed. Washington, DC: National Academy Press.

15. Cabrera RA, Boyd RD, Jungst SB, et al. (2010) Impact of lactation length and piglet weaning weight on long-term growth and viability of progeny. J Anim Sci 88, 2265-2276.

16. Hess HA, Corl BA, Lin X, et al. (2008) Enrichment of intestinal mucosal phospholipids with arachidonic and eicosapentaenoic acids fed to suckling piglets is dose and time dependent. J Nutr 138, 2164-2171.

17. Garces R \& Mancha M (1993) One-step lipid extraction and fatty acid methyl esters preparation from fresh plant tissues. Anal Biochem 211, 139-143.

18. Zhou Y, Nijland M, Miller M, et al. (2008) The influence of maternal early to mid-gestation nutrient restriction on long chain polyunsaturated fatty acids in fetal sheep. Lipids $\mathbf{4 3}$, $525-531$

19. Brenna JT \& Tyburczy C (2010) Identification of FAME Double Bond Location by Covalent Adduct Chemical Ionization (CACI) Tandem Mass Spectrometry. AOCS Lipid Library. http://lipidlibrary.aocs.org/topics/caci_ms/index.htm

20. Pfizer (1999) Internal Study Report no. 3121C-60-99-227. Kalamazoo, MI: Pfizer, Inc.

21. Pfizer (1999) Internal Study Report no. 3121C-60-99-223. Kalamazoo, MI: Pfizer, Inc.

22. Leonard SG, Sweeney T, Bahar B, et al. (2010) Effect of maternal fish oil and seaweed extract supplementation on colostrum and milk composition, humoral immune response, and performance of suckled piglets. J Anim Sci 88, 2988-2997.

23. Accensi F, Pinton P, Callu $\mathrm{P}$, et al. (2006) Ingestion of low doses of deoxynivalenol does not affect hematological, biochemical, or immune responses of piglets. J Anim Sci 84, 1935-1942.

24. Marin DE, Taranu I, Bunaciu RP, et al. (2002) Changes in performance, blood parameters, humoral and cellular immune responses in weanling piglets exposed to low doses of aflatoxin. J Anim Sci 80, 1250-1257.

25. Salem N Jr, Wegher B, Mena P, et al. (1996) Arachidonic and docosahexaenoic acids are biosynthesized from their 18-carbon precursors in human infants. Proc Natl Acad Sci U S A 93, 49-54.

26. Innis SM (2005) Essential fatty acid transfer and fetal development. Placenta 26, Suppl. A, S70-S75.
27. Fleith M \& Clandinin MT (2005) Dietary PUFA for preterm and term infants: review of clinical studies. Crit Rev Food Sci Nutr 45, 205-229.

28. Huang MC, Brenna JT, Chao AC, et al. (2007) Differential tissue dose responses of $(n-3)$ and (n-6) PUFA in neonatal piglets fed docosahexaenoate and arachidonoate. $J$ Nutr 137, 2049-2055.

29. Carlson SE, Werkman SH, Peeples JM, et al. (1993) Arachidonic acid status correlates with first year growth in preterm infants. Proc Natl Acad Sci U S A 90, 1073-1077.

30. Carlson SE (1996) Arachidonic acid status of human infants: influence of gestational age at birth and diets with very long chain $n-3$ and $n-6$ fatty acids. J Nutr 126, Suppl. 4, 1092S-1098S

31. Kuczmarski RJ, Ogden CL, Grummer-Strawn LM, et al. (2000) CDC growth charts: United States. Adv Data 314, 1-27.

32. Bassaganya-Riera J, Guri AJ, Noble AM, et al. (2007) Arachidonic acid-and docosahexaenoic acid-enriched formulas modulate antigen-specific $\mathrm{T}$ cell responses to influenza virus in neonatal piglets. Am J Clin Nutr 85, 824-836.

33. Williams GT, Jolly CJ, Kohler J, et al. (2000) The contribution of somatic hypermutation to the diversity of serum immunoglobulin: dramatic increase with age. Immunity 13, 409-417.

34. Butler JE, Sun J, Weber P, et al. (2000) Antibody repertoire development in fetal and newborn piglets, III. Colonization of the gastrointestinal tract selectively diversifies the preimmune repertoire in mucosal lymphoid tissues. Immunology 100, 119-130.

35. Calder PC (2006) n-3 Polyunsaturated fatty acids, inflammation, and inflammatory diseases. Am J Clin Nutr 83, Suppl. 6, 1505S-1519S.

36. Cray C, Zaias J \& Altman NH (2009) Acute phase response in animals: a review. Comp Med 59, 517-526.

37. Wagstrom EA, Yoon KJ \& Zimmerman JJ (2000) Immune components in porcine mammary secretions. Viral Immunol 13, 383-397.

38. Curtis J \& Bourne FJ (1973) Half-lives of immunoglobulins $\operatorname{IgG}, \operatorname{IgA}$ and IgM in the serum of new-born pigs. Immunology 24, 147-155.

39. Llamas Moya S, Boyle LA, Lynch PB, et al. (2007) Age-related changes in pro-inflammatory cytokines, acute phase proteins and cortisol concentrations in neonatal piglets. Neonatology 91, 44-48.

40. Furugouri K (1974) Kinetics in iron metabolism in piglets. J Anim Sci 38, 1249-1256. 